\title{
Etnografías y contextos islámicos \\ Apuntes sobre puntos de vista nativos y miradas postcoloniales en Marruecos
}

\author{
Ethnographies and Islamic contexts
}

Notes on the native's points of view and postcolonial visions in Morocco

Silvia Montenegro*

\begin{abstract}
Resumo: Este artigo apresenta algumas reflexões sobre a prática etnográfica no Marrocos contemporâneo. Com base no meu trabalho de campo, o texto analisa o ponto de vista nativo de alguns informantes em relação à tarefa dos antropólogos e outros "observadores" das suas culturas. Ao menos tempo, analisamos o discurso dos intelectuais locais no que diz respeito às abordagens antropológicas "ocidentais" do estudo do Islã no Marrocos. Assim, o trabalho explora os supostos, tensões e ambiguidades que subjazem à interação entre observadores e observados.
\end{abstract}

Palavras-chave: etnografias; Marrocos; Islã; informantes

Abstract: This article presents some reflections on the ethnographic practice in contemporary Morocco. Based on my own fieldwork experiences, the paper analyzes some informant's viewpoints about the task of anthropologists and other "observers" of their culture. Furthermore, I examine the discourse of local intellectuals about "Western" anthropological approaches to the study of Islam in Morocco. The text explores some of the assumptions, tensions and ambiguities behind the interplay between observers and observed.

Keywords: ethnographies; Morocco; Islam; informants

* Doutora em Sociologia (IFCS/UFRJ), Pesquisadora do Consejo Nacional de Investigaciones Científicas y Técnicas (Conicet, Argentina), Professora do Departamento de Antropologia, Universidad Nacional de Rosario, Argentina. Pesquisadora associada do Institut des Etudes Hispano Lusophone, Université Mohammed V Agdal, Rabat, Marrocos. Áreas de pesquisa: religião, etnicidade, diásporas, fronteiras, culturas e transnacionalismo.<silviamontenegro@, express.com.ar>.

\begin{tabular}{|l|l|l|l|l|l|}
\hline Civitas & Porto Alegre & v. 12 & n. 3 & p. 489-505 & set.-dez. 2012 \\
\hline
\end{tabular}


Actualmente, resultaría redundante hacer referencia a la discusión sobre las miradas orientalistas y su relación con posiciones etnocéntricas en lo que respecta al conocimiento producido sobre el Islam y las sociedades musulmanas. El debate suscitado entre los acusados de defender posturas orientalistas y sus acusadores parece, por lo menos, haberse atenuado. Y si bien los elementos que supuestamente definían la mirada "orientalista" tanto europea como estadounidense (como la homogeneización esencialista y exotizante, la concepción del mundo musulmán como reverso de occidente, las ideas de incompatibilidad entre Islam y democracia, la preeminencia de análisis teórico sin abordaje empírico, etc.) pueden reaparecer en el discurso periodístico, sobre todo en la forma de asociación entre Islam y formas de violencia, hoy son amplia y generalmente vistos como "no académicos" y teñidos de intencionalidad política.

Aquel debate, con auge hacia finales de los '70 y durante los ' $80,{ }^{1}$ representó un cuestionamiento a la relación entre observados y observadores, una problematización de la relación dicotómica entre discurso nativo y miradas externas, siempre teniendo como telón de fondo las discusiones sobre conocimiento y poder. ${ }^{2}$ En la misma época, otro capítulo más específico, pero también más marginal, de ese tipo de diálogo tenso fue elaborado por antropólogos "nativos" (musulmanes) que intentaron criticar el conocimiento producido sobre el Islam, enarbolando la necesidad de crear las bases para una "antropología islámica", amparados en un proyecto más amplio de islamización de las ciencias sociales. ${ }^{3}$ Ese emprendimiento, casi condenado per se a no prosperar dentro del campo general de la antropología, se auto-identificaba con la antropología postcolonial y llevaba al extremo la crítica a la antropología "occidental" sobre el Islam. Cuestionando la separación entre ciencia y religión, pretendía reintegrar ambos saberes y convocar a la producción de un conocimiento antropológico congruente con los valores islámicos, una forma de estudiarse a sí mismos en lugar de ser estudiados por una disciplina tachada de secularizada y unilateral. A pesar de las grandes diferencias entre ambos, el debate sobre el orientalismo y el proyecto de una antropología islámica ponían en cuestión la manera en que las sociedades islámicas y los musulmanes habían sido observados y construidos desde las ciencias sociales y los medios

1 Las publicaciones de Edward Said, Orientalism (1978) y, posteriormente y en referencia a los medios de comunicación, Covering Islam (1981) son centrales para comprender ese debate.

2 Para un análisis crítico y al mismo tiempo valorizador de los textos de Said, ver James Clifford (1995).

3 Ver Akbar Ahmed (1986). Para la polémica entre antropología del Islam y los intelectuales que postularon la construcción de una "antropología islámica", a partir del proyecto de "islamización de las ciencias sociales", ver Silvia Montenegro (2005 y 2007). 
de comunicación "occidentales". Para visiones como la de Friedman, este es un tipo de efecto derivado de un deterioro de condiciones dominantes, donde la deshegemonización del mundo "dominado por occidente" es al mismo tiempo un impulso de deshomogeneización (2001, p. 184) y donde los actos de autodefinición atañen a las políticas de construcción histórica elaboradas por grupos e individuos.

La situación contemporánea, globalizada, de proliferación de flujos mediáticos e intensificación de las interacciones, incorpora como más corrientes esas tensiones entre la manera en que los grupos son descriptos y cómo pretenden auto-presentarse. Este artículo presenta algunas reflexiones breves a respecto de la actual práctica etnográfica sobre el Islam, los puntos de vista nativos, las miradas "postcoloniales" y la consecuencia para la construcción de visiones pretendidamente no etnocéntricas. Sin bien laterales a mi investigación, estas consideraciones surgen de una serie de notas de mi diario de campo. Tomaré dos casos a manera de espacios de reflexión. Identifico algunos aspectos de la actual práctica etnográfica en Marruecos a partir de algunas experiencias personales, de encuentro con visiones críticas de informantes respecto al papel de investigadores extranjeros (básicamente europeos y norteamericanos). Considero también determinadas visiones de intelectuales locales respecto a la producción antropológica "occidental" sobre su propio país, a la luz de una crítica más general sobre las etnografías del Islam. Esta crítica más amplia proviene de antropólogos que, pasando revista a la producción acumulada, destacan trabajos sobre Marruecos como representativos de un modo "tradicional" y exotizante de producir conocimiento antropológico. Conecto ambas cuestiones a partir de la clara diferenciación que mis interlocutores marroquíes, legos y académicos, realizaban cuando conocían mi origen "latinoamericano", los diálogos que se generaban y las expectativas depositadas sobre un posible "punto de vista diferente" que me era atribuido y que influía en mis condiciones de estar en el campo. Es posible que este caso "sirva para pensar" más allá del contexto de las etnografías del Islam. Las problemáticas resaltadas no son extrañas al campo de estudio de la religión en otros contextos, al juego de las pertenencias entre observadores y observados y a los redireccionamientos temáticos y de enfoques con que algunos investigadores dinamizan esta área de estudios.

\section{Informantes informados y crítica experiencial}

Seguramente, el contexto ha cambiado desde las etnografías producidas en la década de ' 60 , '70 y ' 80 sobre Marruecos. No sólo por las transformaciones sociológicas de la sociedad marroquí, importantes en las últimas 
décadas, ${ }^{4}$ sino también porque actualmente es difícil construir objetos de estudio demasiado circunscriptos y localizados sin caer en miradas forzadas. Las formas del "estar alli" parecen haberse transformado e, incluso, multiplicado. Hoy muchas de las tradicionales órdenes sufíes que se expanden por Marruecos tienen sus propios sitios de internet, filmes y folletos de auto-presentación, abren canales en conocidos espacios de difusión donde "suben" filmaciones con sus rituales y reuniones y transmiten en vivo las alocuciones de sus shaykhs para que puedan ser seguidas por miembros situados en otras ciudades o continentes. Así, estos espacios, que fueron más bien descriptos como mundos de contornos nítidos, difunden sus modos de presentación acudiendo a distintos soportes tecnológicos. Esta transformación, abordada por quienes se refieren a la mediación tecnológica de la difusión y amplitud de la esfera de influencia pública del Islam, ${ }^{5}$ tiene consecuencias en la tarea etnográfica. Las presentaciones mediáticas oficiales, de tal o cual grupo, de tal o cual shaykh, son aquellas a las que suele prestarse mayor atención y, en consecuencia, existen numerosos trabajos analizando esta temática. La "web-observación participante" ${ }^{6}$ no es una práctica extraña a la contemporánea etnografía del Islam. Sin embargo, tal vez la arista más interesante, y menos enfocada, sea aquella que se vincula al registro y usos populares de las imágenes de la vida religiosa, en el plano de una especie de "por cuenta propia" que no parece seguir reglas estrictas sobre las formas en que deben presentarse y difundirse los materiales. Así, vemos que también circulan abundantemente filmaciones de los moussems, sesiones de dhikr, peregrinaciones, fiestas religiosas, rituales de transe, etc. muchas veces realizadas con teléfonos celulares o cámaras de fotos por los propios sujetos que participan en estas actividades o asisten como público a las mismas y que se difunden por redes no ligadas a espacios institucionales. Lo anterior altera la construcción de objetos de estudio sobre los que pesaba la fascinación de lo "oculto", secreto e inaccesible, que sólo podía ser narrado y descripto a través del acceso exclusivo de quien ha llegado a estar ahí. Las etnografías actuales pueden incluir esas dimensiones de incorporación de formas de auto-registrar en imágenes la vida religiosa institucional y no institucional, así como los fenómenos de la participación a distancia.

4 Para un estudio de las transformaciones contemporáneas de la sociedad marroquí ver Cohen y Jaidi (2006)

5 Para este tema, aunque centrado más en la difusión mediática oficial de ciertos discursos, puede consultarse J. Anderson y González Quijano, 2006.

6 Para una discusión metodológica sobre la participant webobservation en la antropología del Islam, ver Varisco, 2007. 
En este contexto, donde los actores sociales se involucran activamente, llamo "informantes informados" a sujetos que, por diversas circunstancias, han elaborado opiniones y posiciones reflexivas respecto a la tarea de los antropólogos en su medio. Se trata de individuos que parecen dispuestos a explicitar sus expectativas sobre el trabajo de interpretación en el que colaboran o pueden colaborar con los antropólogos. Me detendré en algunas experiencias de trabajo de campo donde, fuera de los espacios institucionales académicos, encontré personas que expresaron visiones críticas sobre la manera en que puede ser observada su cultura o religión, ofreciendo una retórica de presentación que dialogaba por contraste con una acentuada desconfianza depositada en las "miradas externas".

Mientras estaba realizando una estancia de investigación posdoctoral en Marruecos, pasé algunos días en una ciudad llamada Sefrou, relevando en la Biblioteca Municipal un material bibliográfico que necesitaba para mi trabajo. ${ }^{7}$ El primer día, en las cercanías de la biblioteca, fui interpelada por una persona que preguntó a que se debía mi presencia en el pueblo. Luego de mi breve presentación como antropóloga, mi interlocutor rápidamente recordó que en el pasado Sefrou había sido visitada por muchos antropólogos, "todos americanos que se instalaban aquí para que alguien les explique las cosas de la religión", dijo que por aquel entonces era demasiado joven pero que había personas ahora aún más viejas que él que recordaban muy bien a esos visitantes. Ahmed fue de gran ayuda durante mi estancia en Sefrou ya que él mismo tomó prestados materiales de la biblioteca para que yo pueda realizar las copias e, incluso, me contactó con personas que tenían algunos libros que podían ser de mi interés. Aunque no había ido a la escuela y sólo hablaba en bereber y árabe marroquí, destacó que podía leer en árabe, francés e inglés y preguntó si yo podía facilitarle los libros que él creía que los antropólogos norteamericanos debían haber escrito sobre Sefrou, pues dijo tener curiosidad por saber lo que habían dicho sobre su ciudad. Ahmed recordaba los nombres de Paul Rabinow y "el otro anterior llamado Clifford...", además de referir dónde vivían y otras anécdotas, difundía ciertas "mitologías" sobre estos antropólogos y el uso de las letrinas, las cuales le resultaban muy divertidas para discurrir sobre las dificultades de adaptación que creía propias de cualquier extranjero.

Él y otros miembros de su familia fueron a buscarme algunas veces a la casa donde estaba hospedada, querían que viese donde vivían antes los judíos

7 Entre 2009 y 2010 pasé 8 meses en una estancia de investigación postdoctoral en Marruecos, gracias a una beca del Conicet. Regresé posteriormente, en 2011 y 2012 para participar de otras instancias de investigación más acotadas, a partir de un convenio entre mi universidad y la Universidad Mohammed V- Agdal - de Rabat. 
que ya no estaban en la ciudad, la marca de donde había llegado el agua en la inundación de 1950, que visite el centro de ex combatientes de la guerra de Indochina, los nómades que vivían temporalmente en las montañas o que me entere de las actividades realizadas en torno a la fiesta de la cereza, que es un importante producto local, cosas que consideraban fundamentales para conocer el lugar. También deslizaron que a los extranjeros les llamaba la atención el culto de los santos y preguntaron si también yo querría escribir sobre eso, advirtiendo que tal o cual marbūt ("santo"), que antes era importante, había experimentado una merma de devotos debido a tales y cuales circunstancias, mientras que otros de la región se habían posicionado con más fuerza. Sus conversaciones giraban en torno de los grandes cambios históricos que habían ocurrido en la ciudad, antes y después de la presencia francesa, antes y después de la inundación, antes y después de la ida de los judíos o las diferencias entre la etapa de Hassan II y Mohammed VI. Aunque sabían que yo no estaba realizando un trabajo sobre Sefrou, manifestaron que un estudio sobre la ciudad debería incluir todos esos aspectos. Al hacerlo, expresaban elementos centrales de la interpretación que hacían de su propio espacio, con la expectativa de que las otras interpretaciones "comprendan" la relevancia de los aspectos que ellos destacaban.

En otros contextos de investigación, también en Marruecos, puede conocer las representaciones que algunas personas comunes y no letradas tenían respecto de los antropólogos y sus temas de investigación. Incluso en algunos parajes un tanto aislados de las ciudades pude recabar opiniones o expectativas sobre aquellos que allí, o en otras regiones, se presentaban para realizar observaciones o se interesaban de algún modo sistemático por la cultura y tradiciones. Una de las miradas más críticas sobre la actividad de los antropólogos me fue referida durante una entrevista con un informante en una aldea del sudeste del desierto marroquí. En medio de una conversación sobre la cultura gnawa y las relaciones entre música y religión, mi informante, con la intención de "colaborar" con mi trabajo, subrayó: "no creas en las historias que cuentan los antropólogos, les gusta mucho contar historias de las cosas que para ellos son extrañas o no comprenden, no creo en sus historias". Aunque él siempre había vivido entre esa aldea y otras cercanas, vinculado a las actividades propias de la ejecución de la música gnawa, había viajado a Nigeria y pasado un tiempo en otras ciudades de Marruecos y fue en alguno de esos circuitos que conoció antropólogos extranjeros interesados en su tradición cultural. Lo que me llamó la atención fue la mirada crítica sobre los temas que, según él, les interesaban a los antropólogos, ya que "las cosas les interesan porque les resultan extrañas" y, en su visión, tal era el caso de los rituales de transe, fundamentales en la práctica religiosa de los gnawa y también del culto de los santos, en relación al resto 
de Marruecos. Mi informante utilizó unas simples palabras para resumir ese interés que atribuía a los antropólogos extranjeros, que evaluó como recurrente y del que dijo sentirse agotado: "jnun...jnun ... marbüt... marbüt...marbūt ". ${ }^{8}$ Posteriormente, desvió el discurso a lo que él sí consideraba importante en su aldea: los problemas vinculados a la educación, el trabajo y la dureza de la vida, colocándolos como estructurantes de la dinámica de la aldea. Incluso, yendo aún más lejos, hizo referencias a visiones que catalogó como "colonialistas" y de atracción por lo extraño.

Otra persona de ese pueblo, a quien yo conocía de una etapa anterior de trabajo de campo, mencionó que, habiendo pasado un tiempo trabajando en Casablanca y otras ciudades de Marruecos, había conocido otros "profesores extranjeros que estudiaban culturas". Al recordar esos encuentros refirió: "conocí una francesa, viajamos juntos en un taxi, ${ }^{9}$ creía saberlo todo, dijo haber escrito dos libros sobre la religión en Marruecos". Aseguró que aún sin haber visto esos libros, podía adivinar que los temas de esas publicaciones seguramente destacarían las cuestiones exóticas, dado que "lo exótico es lo que vende". Prosiguió su relato diciendo: "hace no mucho tiempo conocí una norteamericana, estaba haciendo un trabajo sobre una región cercana del desierto, sobre la religión, estaba acompañada de un asistente bereber, alguien que no era de la zona que ella quería estudiar". Ese último detalle lo condujo a dudar de los posibles buenos resultados de ese trabajo. Afirmó que, con ese asistente, la norteamericana corría la misma suerte de aquellos que se aventuran desprevenidos en una tienda de alfombras, "intentarán venderle una cualquiera, diciéndole que es del tiempo del Profeta". Prosiguió reflexionando sobre cómo haría él mismo un buen estudio, expresando la fórmula que él consideraba necesaria para realizar un trabajo de investigación de calidad: "para hacer un buen trabajo hay que hablar con la mayor cantidad de gente posible y luego analizar todo lo que dicen, hay que dormir en el suelo, comer con las manos, estar siempre con las personas y nunca valerse de intermediarios". De hecho sus breves interacciones lo estimularon a imaginar cómo sería emprender un estudio de esta naturaleza y arribar a la idea de un modelo adecuado de realizar esta tarea.

Otras anécdotas e historias recabadas en el trabajo de campo me permitieron conocer también algunas representaciones construidas en torno a

8 Los jnun, criaturas o seres no visibles, tanto buenos como malos que, en esta última versión, pueden intervenir en experiencias de transe y posesión en la práctica religiosa gnawa. Marbüt alude a la figura de un "santo".

9 Se refería a un viaje en "grand taxi", que transporta 6 personas y se utiliza popularmente para realizar viajes interurbanos a bajo costo. 
la forma de presentarse de algunos antropólogos. Dos hombres me dijeron que nunca olvidarían que a una Asociación cercana a su ciudad llegó un grupo de estudiantes alemanes de antropología, guiados por su profesora, estaban allí para realizar una práctica de trabajo de campo. Lo que llamó la atención de los locales fue que todas las mujeres alemanas usaban el hijab, aunque ninguna de ellas era musulmana. Según relataron, la antropóloga que guiaba al grupo les había explicado que durante la visita todas cubrirían su cabello por "respeto a la cultura local" y como parte del proceso de experiencia cultural. Mis interlocutores consideraron aquello como un algo extraño, pues dijeron sentirse ante un contingente de "personas disfrazadas". De este modo, a lo acordado por la antropóloga y sus estudiantes subyacía la expectativa de una interpretación direccionada a infundir confianza a través de la muestra de respeto y adaptación para con los usos locales. No obstante, aquello fue decodificado como una conducta inexplicable, desatando, cada vez que se recordaba el hecho, una serie de conjeturas jocosas e imaginativas sobre los verdaderos motivos que las visitantes tendrían para cubrirse.

Con frecuencia, nuestras reflexiones sobre la práctica etnográfica se traducen en ejemplificaciones metodológicas y se condensan en relatos sobre cómo llevar a buen puerto la negociación de una entrada al campo, cómo el antropólogo acabó conquistando la confianza de los sujetos y qué estrategias desplegó para moverse exitosamente en el espacio clasificatorio de las diferencias culturales que los informantes le asignaron. ${ }^{10}$ Lógica, y necesariamente, ese relato sólo puede construirse a partir de cierta autoinmunidad para con las interpretaciones y percepciones muchas veces no manifiestas y efectivamente construidas por los observados. En las miradas críticas que antes mencionábamos, encontramos desplegada la reflexividad de "los nativos" no en espacios donde deben negociar, en tiempo presente, la presencia de un observador-antropólogo y confrontar códigos de clasificación, sino como rememoración o saldo de experiencias concretas, enmarcadas en interpretaciones más amplias y generales. Se trata de aseveraciones respecto de las formas en las que consideran que son observados y de un conjunto de expectativas sobre la relevancia que será otorgada a los temas que ellos mismos destacan como importantes. La condena a la exotización se activa a través de esa no correspondencia en la jerarquización de tópicos y en la percepción de que aquello que resulta ordinario, y corriente, del otro lado pueda ser resaltado como extraordinario y llamativo.

${ }^{10}$ El relato de Paul Rabinow (1977) sobre su experiencia de campo en Marruecos, representa una excepción a ese relato metodológico lineal. 
En los párrafos que siguen haremos alusión a una crítica más estructurada que, no obstante, comparte algunos presupuestos de esta crítica espontánea que no está informada por teorías o debates sino por experiencias e interpretaciones.

\section{Crítica "postcolonial" y miradas locales}

Desde la década del ' 50 el Islam en Marruecos fue un tópico destacado dentro de la antropología. Por un lado, los trabajos del antropólogo estadounidense David Montgomery Hart ${ }^{11}$ y del británico Ernest Gellner se centraron en las tribus bereberes del alto Atlas y en la región del Riff, a partir de investigaciones sostenidas durante décadas en el área de la antropología política y de los estudios de la religión. Por otro lado, desde la década del 1960, antropólogos norteamericanos desarrollaron importantes investigaciones en terreno, entre éstos estaban Clifford Geertz, Lawrence Rosen, Hildred Geertz y Paul Rabinow, que centraron sus etnografías en las regiones al pie del Medio Atlas, desde el "centro de operaciones" creado por Geertz en el pueblo de Sefrou, pero incluyendo áreas aledañas. Realizando su trabajo de campo en 1968, Vincent Crapanzano produjo un completo y célebre análisis de la práctica religiosa Hamadsha en el área de Meknes, relacionada con el transe y la cura y otros trabajos posteriores enmarcados en la etnopsiquiatría utilizando el método autobiográfico, como es el caso de Tuhami. Dale Eickelman, investigó sobre la transmisión del saber islámico, sus instituciones y las relaciones de poder en torno a ese tópico, así como sobre algunos centros de peregrinación. Esos abordajes cubrieron temáticas como la organización tribal y su relación con el Islam, la transmisión del conocimiento religioso, las transformaciones de la religión luego del período de la independencia, enfoques etnopsiquiátricos, los cultos de santos, las diferencias entre el Islam erudito y el popular, el Islam de las cofradías y sus prácticas rituales. ${ }^{12}$

Esa producción, bien conocida en la antropología a nivel internacional, no tuvo una fuerte influencia de conjunto entre los intelectuales marroquíes, salvo entre aquellos que tuvieron contacto o se formaron en espacios académicos

${ }^{11}$ Hart fue quien pasó más tiempo entre los bereberes del Atlas, alrededor de 20 años, radicándose luego en España hasta su muerte en el año 2001. Realizó también trabajos comparativos sobre el Islam y la organización tribal entre los pujtunes de Pakistán.

12 Algunos de los trabajos producidos por esos autores: Dale Eickelman, Moroccan Islam: tradition and society in a pilgrimage center, University of Texas Press, 1976; Knowledge and Power in Morocco, Princeton University Press, 1985. Clifford Geertz, Islam Observed, New Haven: Yale University Press, 1968. Clifford. Geertz, Hildred Geertz y Lawrence Rosen, Meaning and Order in Moroccan Society, Cambridge University Press, 1979. Paul Rabinow, Reflection on fieldwork in Morocco, University of California Press, 1977. Ernest Gellner, Saints of the Atlas, Chicago University Press, 1969. Vincent Crapanzano, The Hamadsha, University of California Press, 1973; Tuhami, University of Chicago Press, 1980. 
de Europa o Estados Unidos, o fueron interlocutores durante las décadas en que algunos de aquellos antropólogos permanecieron en el terreno. Uno de los motivos de esta falta de repercusión local se relaciona también al carácter tardío de las traducciones de estos libros al francés, ${ }^{13}$ así como al escaso desarrollo local del campo de la sociología y antropología. Tal vez por ello el coloquio en homenaje a Clifford Geertz, realizado en Sefrou en el año 2000, y que representó la última visita del antropólogo a la ciudad que frecuentó entre 1963 y 1986, haya estado organizado por una universidad norteamericana y pasado bastante desapercibido en los círculos locales, aunque contara con la presencia de algunos intelectuales marroquíes. ${ }^{14}$

No obstante, existen otros motivos, vinculados a la visión de ciertos sectores locales respecto de la antropología. Como fue señalado (Gonzales Alcantud, 2001; Berlanga Adell, 2006), hasta recientemente, y en muchos círculos intelectuales de la región, la antropología fue vista como una extensión de las prácticas coloniales o neocoloniales o, en el mejor de los casos, como una observación externa exotizante que generaba desconfianza. Según Dialmy (2005), algunos sectores consideraron que bajo el protectorado francés, e incluso posteriormente, la antropología había folklorizado el Islam, al interesarse predominantemente por las formas tribales, tradicionales e históricas que incorporaban ritos locales. Esto habría conducido a destacar temas como el culto de los santos, los ritos de iniciación y prácticas que insinuaban que la propia religión expresaba el consenso cultural.

Las representaciones sobre el Islam construidas a partir de ciertos estudios antropológicos realizados en Marruecos también fueron objeto de revisiones críticas, esta vez en el contexto de intentos por renovar ese campo de estudio. El antropólogo estadounidense Varisco (2005), por ejemplo, insiste en pasar revista a la producción antropológica sobre el Islam escogiendo cuatro autores, tres de los cuales desarrollaron sus investigaciones también en Marruecos: Geertz, Gellner y la socióloga marroquí Fátima Mernissi, siendo el cuarto Akbar Ahmed y su propuesta de una antropología islámica. Aunque los dos primeros representan miradas hacia otros y los dos últimos reflexiones sobre sus propias sociedades, Varisco los asimila por haber producido representaciones sobre el Islam que, según su punto de vista, tendieron a oscurecer la efectiva

13 Ver el artículo de Slyomovics sobre C. Geertz (2009).

${ }^{14}$ El coloquio, denominado "Cultures, Sociétés et Territoires. Hommage a Clifford Geertz" fue coordinado por Abdellah Hammoudi, antropólogo marroquí radicado en Estados Unidos, profesor en la universidad de Princeton. Revisando la copia mimeográfica del encuentro, realizado del 4 al 6 de marzo del 2000, puede notarse que los temas son variados y, en general, las alusiones y recuperación de la obra del autor homenajeado son escasas. 
comprensión de esta religión. Uno de los problemas que señala es el efecto producido por la generalización a partir de casos no reconocidos como tales, lo cual habría empañado la percepción del Islam en cuanto fe atravesada por diferentes culturas y embebida de múltiples tradiciones. La consecuencia de las representaciones producidas por estos abordajes habría sido la de generar un "Islam obscured". De allí que, intentando asumir una postura fuertemente anti-esencialista, Varisco subraye que categorías tales como "Islam" no tienen sentido para la antropología ya que lo único realmente existente son los musulmanes, lo que éstos hacen e interpretan. Desde esa perspectiva, el análisis antropológico del Islam, que la propia antropología habría oscurecido a través de las múltiples representaciones creadas, debería reorganizarse fundándose en reflexiones basadas en las lecciones que la antropología podría extraer de su pasado. Éstas pasarían por discutir las formas adecuadas de realizar trabajo de campo, la unidad y variedad del Islam y la forma de producir investigaciones luego de la crítica al orientalismo y de las influencias de la mirada postcolonial.

Estas discusiones, que parecen regresar sobre críticas ya realizadas, no parten de la defensa de puntos de vista nativos sino de la crítica de antropólogos inscriptos en el campo de la antropología del Islam. No obstante, también señalan el problema de la folklorización del Islam como marca de muchos estudios realizados, así como el uso de categorías homogeneizantes. Aunque el italiano Marranci (2008) también acusa a la antropología del Islam de padecer de esencialismo, explica esta cuestión a partir de la posición que estos estudios tuvieron dentro del campo de los estudios de la religión a comienzos de los años 1960. La fase de estudios que él considera más exotizante coincidiría con la época en que los pocos antropólogos que por entonces se dedicaban a la investigación empírica de estos temas necesitaron reafirmar y defender su identidad dentro de la disciplina. Esto habría producido una tendencia a concentrarse en el estudio de los sistemas simbólicos y en la exaltación de la cultura, como espacios ya legitimados en el estudio de las religiones. Esta tendencia supuestamente explicaría que los antropólogos dedicados a estudiar las sociedades musulmanas en esa etapa "hayan encontrado refugio en las aldeas, entre los santos sufíes, los miembros de las tariqas y en áreas como el parentesco y el folklore" (op. cit, p. 144). El esencialismo se habría forjado, entonces, como un padecimiento de la fase exótica del estudio del Islam pero llegaría a impregnar parte de los estudios actuales. En la etapa exótica, la esencialización habría conducido a que la estructura social y la organización política de las sociedades musulmanas sea interpretada como estrechamente vinculada a aspectos de la religión islámica. 
A diferencia de Varisco, para Marranci no se trata de enmendar el pasado esencialista sino de reconocer la necesidad de un desplazamiento temático: del Islam hacia los musulmanes, de las aldeas y los santos hacia las metrópolis y los inmigrantes. Aun así, en esos nuevos contextos la mirada esencialista reaparecería cuando las identidades musulmanas son interpretadas como productos del Islam como religión. Cualquiera sea entonces el contexto, el problema radicaría en enfocar el Islam como un sistema simbólico cultural, cuestión que, según Marranci, no ha ocurrido en el caso del estudio de otras religiones. Desde ese punto de vista, términos asociados como “comunidad musulmana", más allá de su carácter emic o etic, también operarían a favor del esencialismo. Un aspecto más interesante vinculado a la necesidad de desplazamientos temáticos, es el del estudio del género en el Islam. Marranci intentará demostrar que en ese subcampo el género siempre es ecuasionado exclusivamente al género femenino y que no existen estudios que incorporen el análisis de la masculinidad, la homosexualidad y todo aquello dejado de lado o minimizado. Lo que esta revisión crítica propone es pensar al Islam no como una tradición religiosa sino como un mapa de discursos, derivado de las distintas maneras en que las personas se sienten musulmanas.

La visión crítica de cierto sector de intelectuales magrebíes señalada por Dialmy (2005) anteriormente, de la antropología como folklorizante y asociada a las prácticas coloniales, se relaciona con las críticas que acabamos de revisar. Ambas claman por el fin de los enfoques exotizantes que se vinculan al privilegiamiento de ciertos temas que traen consigo una serie de enfoques y categorías de análisis.

Siguiendo con el caso de los estudios en el espacio local de Marruecos, a pesar de que en general es admitida la debilidad del campo disciplinar de la sociología y la antropología y una escasa producción sobre el terreno, existen hoy diversos trabajos realizados por intelectuales locales. Las temáticas y abordajes difieren de las investigaciones que las críticas anteriores catalogaban como pertenecientes al período de los estudios exotizantes. Estos estudios difieren, sobre todo, en cuales son los temas considerados importantes y característicos de la dinámica religiosa local. El Islam contemporáneo y en contexto urbano es uno de los tópicos enfocados, su relación con los valores, la política y las formas de familia. Varios trabajos señalan los aspectos del cambio social en el Marruecos contemporáneo, las diferencias en la práctica y conocimiento religioso en las distintas generaciones, la interpenetración de la vida rural y urbana, la valorización de signos de la religiosidad y cambios en la percepción de la autonomía 
individual. ${ }^{15}$ Otros temas también se relacionan con las diferencias de género y edad en las creencias y prácticas religiosas, la reestructuración en la enseñanza y transmisión del saber islámico, el surgimiento de grupos islamistas en Marruecos, el Islam y la monarquía. Las relaciones entre Islam, sexualidad, salud y género, entre feminismo, islamismo y sufismo también integran estudios producidos localmente (Ababou, 2005; Faoubar, 2005; Dyalmi, 2005, 2000 y 2008; Tozy, 1999).

Es evidente que ese tipo de trabajos destacan otras problemáticas, no sólo las relacionadas con el Islam en su forma contemporánea sino en el plano de un contexto mayor de transformaciones y tendencias. Como señala Dialmy (2005) al preguntarse por la posibilidad de que el Islam sea estudiado por intelectuales locales, el emprendimiento parece diferente en una sociedad de pertenencia donde el Islam es a la vez la religión de Estado, la principal referencia pública, la experiencia cotidiana y el lazo social, es en síntesis un capital simbólico puesto a funcionar bajo diferentes formas. Algunos antropólogos, como Tozy (2006, p. 106), también señalando la importancia de los temas contemporáneos, prefieren considerar la necesidad de una relación pacífica entre esa herencia de la antropología y las ciencias sociales actuales. En ese caso, la propuesta pasa por recuperar la contribución de las descripciones y los datos recolectados más allá de la manera en que fueron interpretados. Los presupuestos "colonialistas" serían irrelevantes, dado que lo que cuenta son los hechos y las observaciones sobre los cuales podrían realizarse otras interpretaciones. En este último caso, se postula que la recuperación de esa tradición pasa por generar otras interpretaciones sobre los mismos "hechos" y datos ya relevados.

\section{Conclusiones}

Tanto la primera crítica a la que aludimos, la elaborada por sujetos fuera del contexto académico, como aquella realizada en relación a la forma en que las ciencias sociales interpretaron el Islam parecen poner en cuestión aspectos consonantes. En el primero de los casos se trata de una lectura "más espontánea" que toma por asidero alguna experiencia de contacto con quienes, provenientes

\footnotetext{
${ }_{15}$ Para un panorama sobre esos cambios puede consultarse Rahma Bourqia (2010), según los resultados de un proyecto de investigación que incluye una encuesta a nivel nacional: "El apego a la religión se manifiesta a través de la aplicación del pilar del islam: la práctica de la oración. En la Encuesta Nacional sobre los Valores puede comprobarse que el 72,4\% de los entrevistados rezan de modo habitual. Entre estos cambios se constata un cierto retroceso del islam popular en beneficio de un islam ilustrado, en la medida en que el $53,4 \%$ de los encuestados no visitan nunca los santuarios. La progresiva generalización de la educación y la valorización de los signos de religiosidad están relacionadas con un rebrote de manifiesta religiosidad" (p.240).
} 
de otras sociedades, se presentan explicitando la intención de realizar un estudio sobre los otros. En el segundo de los casos, se trata de la elaboración de una crítica informada por las sospechas de orientalismo, colonialismo y otras formas de "incomprensión" a las que se le atribuye intencionalidad política o sobre la cual recaen sospechas de esencialismo folklorizante. Los aspectos comunes se refieren al cuestionamiento de la pretensión del antropólogo u observador de hablar por los otros y saber qué aspectos de la cultura son importantes, vale la pena discutir o son característicos de la misma, pero excluyendo a los sujetos que ahora esgrimen la posibilidad de hablar por sí mismos (Kortländer, 2001). Refiriéndose a los distintos abordajes etnográficos sobre la religión musulmana, el "tradicional" y otro más sensibles a estas críticas, Kortländer argumenta que los que impugan el modelo tradicional afirman que en la antropología las descripciones holísticas de la cultura, en su intento por encontrar características generales, producen cultura y tradición en lugar de analizarlas. Una idea similar subyace a algunas revisiones críticas de la antropología del Islam, como las elaboradas por Varisco y Marranci, donde lo que se ponía en cuestión, a veces de un modo un tanto generalizante, era el tipo de representaciones creadas sobre el Islam y su incidencia en la forma de configurarlo como objeto.

En cierto sentido, se trata de señalar el problema de tratar al Islam como algo indeterminado, sinónimo de cultura, sociedad, tradición, política, estructura social. Justas o injustas para con sus blancos, el conjunto de las visiones críticas parece también descreer de la posibilidad de conocer el todo a partir de una de sus partes, reclamando prudencia en las generalizaciones basadas en trabajos de campo circunscriptos. Tanto en el discurso de los "informantes críticos", a los que aludí en el comienzo de este artículo, como en el de quienes, en el ámbito académico, veían a la antropología del Islam como una extensión de las prácticas coloniales, esa mirada "externa" era atribuida a un origen o a una tradición relacionada, en algunos casos con precisión y en otros más vagamente, con Europa o con Estados Unidos. Esto hacía que en la instancia de los encuentros, al ser revelado un origen diferente del investigador, se susciten comentarios y preguntas relativas a semejanzas y diferencias, que permitieran la asimilación a otro y nuevo espacio clasificatorio.

Fuera del ámbito académico, en los casos a los que hice mención antes, el revelar otro origen parecía generar un cierto grado de diferenciación que permitía explicitar puntos de vista, lanzar ironías o comentarios menos controlados por las reglas de etiqueta. América del Sur, aún para quienes no conseguían situar con precisión su posición geográfica, era, de todos modos, algo distinto de esos otros espacios y esto posibilitaba una cierta soltura al 
establecer críticas hacia las visiones provenientes de aquellos otros orígenes. Tal fue esto lo que me permitió registrar algunos de los ejemplos a los que he hecho alusión. En el medio académico, la diferenciación era mucho más clara y explícita ya sea porque se aludía a que América Latina había ocupado también una posición subordinada en relación a los espacios de poder político y económicos mundiales o porque se afirmaba la posibilidad de un tipo de entendimiento no teñido por concepciones de jerarquía o superioridad cultural.

El paisaje de la diversidad en Marruecos es autoevidente dentro del aspecto común de la adhesión general al Islam. El hecho de prestar o no atención a ese aspecto tal vez no se explique por una posición de origen que entrene al observador para estar atento a ello, sino por una cierta desconfianza en la ilusión de la homogeneidad y en la nitidez de la separación nosotros/ ellos. Las ciencias sociales locales, si bien incipientes en el análisis empírico, señalan que género, edad, clase, lengua, ideologías políticas, movilidades, consumo, formas individualizadas de entender la práctica o la no práctica de la religión, etc. son dimensiones imbricadas y difícilmente eludibles que, como en toda sociedad y contexto, operan en cualquiera de los espacios sociales observados. Una agenda temática que no difiere de aquella que aplicaríamos en nuestras propias sociedades, más sensible a la dinámica de lo que cambia.

Para quien realice una etnografía contemporánea sería difícil no reconocer el desplazamiento, ya no del paso del estudio del Islam al de los musulmanes y del de las aldeas al de las metrópolis sino de reflexionar sobre el ida y vuelta entre varias coordenadas de esa complejidad, cualquiera sea el punto en que decida situarse.

\section{Referencias}

ABABOU, M. The impact of age, generation and sex variables on religious beliefs and practices in Morocco. Social Compass, Louvain, v. 52, n. 1, p. 31-44, 2005.

AHMED, A. Toward Islamic Anthropology. The American Journal of Islamic Social Sciences, v. 3, n. 2, p. 181-230, 1986.

ANDERSON, J.; GONZÁLEZ-QUIJANO, Ives. Technological Mediation and the Emergence of Transnational Muslim Publics. In: SALVATORE, Armando; EICKELMAN, Dale. Public Islam and the Common Good, Leiden: Brill, 2006.

BERLANGA-ADELL, M. Antropología en Marruecos: el poder y la construcción de un campo científico. Arxius, Valencía, n. 14, p. 7-26, 2006.

BOURQUIA, R. Valores y cambio social en Marruecos. Quaderns de la Mediterrània, Barcelona, n. 13, p. 235-244, 2010.

CLIFFORD, J. Sobre orientalismo, Dilemas de la cultura, Barcelona: Gedisa, 1995. 
COHEN, S.; JAIDI, L. Morocco Globalization and its consequences, New York: Routledge, 2006.

CRAPANZANO, Vincent. The Hamadsha, University of California Press, 1973.

CRAPANZANO, Vincent. Tuhami: portrait of a Maroccan. Chicago: University of Chicago Press, 1980.

DIALMY, A. Religious pratice in Morocco, Social Compass, Louvain, v. 52, n. 1, p. 5-12, 2005.

DIALMY, A. Jeunesse, SIDA et Islam au Maroc: les comportements sexuels des Marocains. Casablanca: Ediff, 2000.

DIALMY, A. Les antinomies de la raison islamo-féministe. Le féminisme au Maroc. Casablanca: Toubkal, 2008.

EICKELMAN, Dale. Moroccan Islam: tradition and society in a pilgrimage center. University of Texas Press, 1976.

EICKELMAN, Dale. Knowledge and power in Morocco. Princeton University Press, 1985.

FAOUBAR, M. Réforme et restructuration de l'enseignement de l'islam dans les collèges marocains, Social Compass, Louvain, v. 52, n. 1, p. 45-52, 2005.

FRIEDMAN, J. Historia y política de la identidad, Identidad cultural y proceso global, Buenos Aires: Amorrortu, 2001.

GEERTZ, Clifford. Islam observed, New Haven: Yale University Press, 1968.

GEERTZ, Clifford; GEERTZ, Hildred; ROSEN, Lawrence. Meaning and order in Moroccan Society, Cambridge University Press, 1979.

GELLNER, Ernest. Saints of the Atlas. Chicago University Press, 1969.

GONZALES-ALCANTUD, J. Antropología y democracia. Historia, Antropología y fuentes orales, Barcelona, n. 26, p. 5-22, 2001.

KORTLANDER, J. An Account on the diversity of islamic tradition. Munich: Grin Publishing, 2001.

MARRANCI, G. The anthropology of islam. New York: Berg, 2008.

MONTENEGRO, S. Antropologías del islam y antropología islámica. Etnografías contemporáneas, Argentina, v. 3, n. 3, p. 87-113, 2007.

MONTENEGRO, S. Antropologías postcoloniales: la antropología islámica y la islamización del conocimiento en ciencias sociales. Campos, Paraná, v. 5, n. 2, p. 9-23, 2005.

RABINOW, Paul. Reflection on fieldwork in Morocco. University of California Press, 1977.

ROQUE, M. La complejidad cultural de Marruecos, una herencia Mediterránea. Entrevista a Mohamed Tozy. Quaderns de la Mediterrània, Barcelona, n. 13, p. 105$112,2006$.

SAID, E. Orientalism, New York: Pantheon Books, 1978. 
SAID, E. Covering Islam: how the Media and the experts determine how we see the rest of the world. New York: Pantheon Books, 1981.

SLYOMOVICS, S. Introduction to Clifford Geertz in Morocco: Whay Sefrou? Why anthropology? Why me? The Jounal of North African Studies, v. 14, n. 3-4, p. 317-325, 2009.

TOZY, M. Monarchie et islam politique au Maroc. Paris: Presses de Sciences Po, 1999.

VARISCO, D. Islam Obscured. The rhetoric of anthropological representacion. New York: Palgrame Macmillan, 2005.

VARISCO, D. Virtual Dasein: ethnography in cyberspace. CyberOrient, USA, v. 2, Iss. 1, 2007.

Data de recebimento: 17.08 .2012

Data de aprovação: 28.09 .2012 